\title{
A FORMAÇÃO DE PROFESSORES E OS CURRÍCULOS PRATICADOS EM UM MOVIMENTO DE EDUCAÇÃO POPULAR NA ROCINHA
}

\author{
Rodrigo Torquato da Silva* \\ Rede Municipal de Niterói - RJ
}

\begin{abstract}
RESUMO: A proposta deste artigo é fazer um mergulho nas redes de ações coletivas que atribuem sentidos políticos e pedagógicos aos processos de sociabilidades na favela da Rocinha. Trata-se de uma pesquisa nos/dos/com os cotidianos de um movimento social de educação popular, o Pré-Vestibular Comunitário da Rocinha (PVCR), situado em uma das maiores favelas da América Latina. O objetivo central deste texto é apresentar práticas pedagógicas tecidas no cotidiano do PVCR que forjam uma nova perspectiva de formação de professores, num contexto em que as hierarquias tradicionais da relação professor/aluno são quebradas e reinventadas a partir da potência emancipatória presente nos conflitos dos currículos praticados.
\end{abstract}

PALAVRAS-CHAVE: Educação Popular; Favela; Movimentos Sociais

\section{TEACHER TRAINING AND THE SYLLABUSES ADOPTED} IN A COMMUNITY EDUCATION MOVEMENT IN ROCINHA

ABSTRACT: This article looks into the network of collective actions that lend political and pedagogical meaning to sociability processes in Rocinha shantytown. Pré-Vestibular Comunitário da Rocinha (PVCR), a community education movement based at Rocinha, one of the largest shantytowns in Latin America, prepares students for university entrance examinations. The core objective is to present pedagogical practices built on the PVCR experiences that shape a new teacher development/training perspective in a context where traditional teacher-student relation hierarchies are broken and reinvented from the emancipating power born in the conflicts of the adopted syllabus.

KEYWORDS: Popular education, Shantytown, Social movements

\footnotetext{
* É morador da Rocinha. Programa de Pós-Graduação em Educação da UERJ. Mestre em Educação. Professor do Ensino Fundamental da Rede Municipal de Niterói-RJ. Membro do grupo de pesquisa do Laboratório Educação e Imagem da UERJ. E-email: torquatoprof@ig.com.br
} 


\section{INTRODUCุÃO}

O objetivo deste artigo é apresentar práticas pedagógicas tecidas no cotidiano de um movimento social de educação popular, o PréVestibular Comunitário da Rocinha (PVCR), cuja maior potência emancipatória está presente nos conflitos. Esse movimento social tem como principal característica a participação voluntária - não-remunerada -, que faz com que bandeiras políticas e ideológicas se pactuem a partir de conflitos e negociações cuja tônica é a não-eliminação do outro, visto que a perda de participantes significa o distanciamento de um eixo dos objetivos políticos e pedagógicos propostos.

\section{BREVE HISTÓRICO DO MOVIMENTO}

Não é possível iniciar, hoje, uma discussão sobre educação popular em favelas e periferias sem mencionar a luta do povo negro contra a lógica colonizadora, que lhes foi historicamente imposta. Tal lógica, pautada na racialização das relações, e tendo como premissa fundamental a inferiorização do outro, o não-europeu, à condição de nãohumano, gerou campos de tensionamentos nos quais o povo negro, num processo incessante, construiu estratégias de lutas intergeracionais.

Muitos foram os movimentos de lutas silenciados na nossa História. Porém, em 1993, foi criado, na Baixada Fluminense (periferia do Rio de Janeiro), o Pré-Vestibular para Negros e Carentes. Esse movimento social de educação popular surge a partir da constatação de que, no Brasil, o processo de discriminação racial se consolidava não só simbolicamente, mas estatisticamente, a partir de um perverso processo de exclusão, em que o acesso e a permanência na escola aparecem como fatores substanciais. A luta do PVNC', visando a combater essa realidade, pautou-se numa agenda que incluía não só o treinamento para o vestibular ou o simples reforço na escolarização, mas, principalmente, o reposicionamento do povo negro na sociedade brasileira, por meio do acesso à universidade. Não só isso, mas também reivindicar uma universidade que garantisse permanente formação política, que os preparasse para as lutas posteriores, mais ampliadas, numa sociedade que não cessa de discriminá-los. É nesse sentido que entendo o PVNC, como uma continuidade dos processos de lutas, que têm atravessado gerações e se consubstancializado por meio de várias políticas de ação afirmativa, entre as quais o surgimento do sistema de cotas nas universidades públicas, conquistado a partir da luta do Movimento Negro e, sobretudo, da Lei $10.639^{2}$. 
Em 1994, o PVNC atinge outras dimensões e se ramifica em vários núcleos, entre os quais o núcleo Rocinha, que traz no seu bojo toda uma expectativa por ser o quinto núcleo do PVNC e o primeiro na zona sul do Rio de Janeiro, situado em uma das maiores favelas da América Latina. Esse espraiamento trouxe, a reboque, muitas disputas políticas, natural nos processos de consolidação e crescimento dos movimentos sociais de cunho popular.

Durante os primeiros anos de atividade do núcleo Rocinha, foi possível perceber como a dinâmica do cotidiano de um pré-vestibular envolve alunos, professores e coordenação num dos objetivos considerados comuns a todos, que é o caso da preparação para a realização das provas do vestibular. No entanto, as assembléias gerais, que reúnem todos os núcleos do PVNC, bem como as reuniões internas de cada pré, com a participação de todos os seus integrantes, transformam esses fóruns do movimento em arenas de disputa política e ideológica e repercutem no trabalho de politização de alunos, professores e coordenação, o que é considerado um dos diferenciais que influenciam a prática pedagógica dos pré-vestibulares populares.

A especificidade das práticas dos sujeitos participantes dos diferentes núcleos com a percepção diferenciada de suas ações de intervenção foi fundamental, como movimento social, no processo que levou o núcleo Rocinha do Pré-vestibular para Negros e Carentes a se desligar deste movimento e a constituir o Pré-vestibular Comunitário da Rocinha (PVCR), em 1999. O PVCR não abandona, com isso, a concepção de movimento social que o move, mas, a partir desse momento, adota uma intervenção social que altera sua postura político-ideológica, na intenção de atender às especificidades da favela da Rocinha.

Após a ruptura com o PVNC, a coordenação, os professores e os alunos do agora PVCR fazem a opção por outra linha política, passando a incorporar ao discurso do movimento uma perspectiva que vai além das questões raciais, pois, para esse grupo, oriundo, em sua maioria, da própria favela ou das adjacências, outras discussões seriam necessárias para estabelecer uma marca identitária local ao movimento. No entanto, é bom ressaltar que o PVCR só chegou a esse grau de politização ao passar por um processo de amadurecimento, que foi gestado no ventre das estruturas de organização do PVNC.

Sobre essa ruptura, o professor Renato Emerson dos Santos (2003), um dos fundadores do PVCR e pesquisador dedicado a essa causa, confirma o que foi dito, levando-nos a uma reflexão importante, quando 
analisa os embates travados nas assembléias dos núcleos do PVNC ( PréVestibular para Negros e Carentes):

Mesmo em núcleos - como no caso do Rocinha - onde a racialidade não foi assumida enquanto bandeira principal do trabalho, os debates que levaram a isso confrontaram os indivíduos à crítica das relações raciais imanentes à sociedade brasileira - indivíduos que, até então, eram informados apenas pelo senso comum e pela ideologia dominante, o mito da democracia racial. Neste sentido, o processo de socialização instaurado nos pré-vestibulares populares de um modo geral - e não apenas no Pré-Vestibular para Negros e Carentes - passa a ser um momento privilegiado de difusão da consciência do antiracismo. Um ideário que, até bem pouco tempo, era circunscrito a restritos e estigmatizados círculos acadêmicos e de militância dos movimentos negros, encontra-se com a consciência difusa, municiando e fortalecendo a sociedade sobre a necessidade de reversão de um quadro que as ideologias dominantes sempre se esforçaram por silenciar. (SANTOS, 2003b, p.151)

Todas essas questões são discutidas dentro do PVCR e representam um momento em que este núcleo questiona e repensa a orientação da sua ação e inserção dentro e fora da comunidade. O PVCR começa a avaliar como se dava sua participação no movimento do PréVestibular para Negros e Carentes e a debater sobre a predominância da questão racial no cotidiano. Tal avaliação permitiu (re)pensar outra proposta de trabalho fundamentada em bases ideológicas mais amplas, mas, de certa forma, não anula a discussão racial.

Nesse sentido, uma das primeiras discussões que emerge entre os integrantes do grupo do "pré-Rocinha" (alunos, professores e coordenadores) é a escolha de um novo nome. Isso remete, inclusive, a uma reflexão identitária que envolve a relação entre colaboradores (voluntários), público-alvo e a localização do "pré", no espaço geográfico e social da Rocinha.

O nome Pré-Vestibular Comunitário da Rocinha (PVCR) tenta registrar a importância e a significação dada ao caráter "comunitário" deste núcleo. Durante as discussões do grupo, são apontados como princípios orientadores não somente as características fundantes, herdadas do PVNC, entre elas a definição da discussão racial como um pilar de sustentação do movimento. É possível, também, indagar se essa concepção de comunidade não é resquício da ideologia dos "Trabalhos Comunitários", que permeou e marcou as ações políticas na Rocinha, segundo Segala (1991), na década de 1980. O fato é que foram lançadas, no PVCR, novas propostas (objetivos), idéias e orientações políticas voltadas para a especificidade da Rocinha, como favela, assumindo, assim, 
outras ações no âmbito da educação popular, vislumbrando uma possível alteração no projeto político e pedagógico para outros tipos de intervenção dentro desta localidade.

Assim, foram pensadas e elaboradas novas estratégias de ação na tentativa de aproximação com a favela. Nesse sentido, houve mudanças nas relações com as instituições que cedem o espaço físico que abriga o "pré". Ampliou-se a divulgação do PVCR por meio de cartazes espalhados por todas as partes da Rocinha, o que resultou na duplicação do número de inscritos. Tal fato exigiu a discussão sobre um processo seletivo, o que possibilitou pensar no perfil do aluno para o PVCR. Cabe ressaltar que, embora tal perfil inclua todos os alunos potenciais, por uma questão de falta de infra-estrutura fez-se necessário um processo seletivo que indicasse quais membros do público-alvo ingressariam no PVCR, num primeiro momento, e quais aguardariam a chamada, a partir de uma lista de espera. Foi preciso ainda pensar em estratégias para tentar suprir as defasagens escolares, oriundas de um processo de escolarização precário dos alunos que foram selecionados. Além disso, foi necessário conscientizá-los de que o curso só existe, e continuará existindo, se houver constante renovação dos voluntários-colaboradores. E que o desejo dos atuais colaboradores é de que se possa aumentar o número de voluntários oriundos da própria favela, visto que o impacto que isso causa é de extrema importância para os alunos das gerações seguintes.

\section{PLANEJAMENTO PEDAGÓGICO E CURRÍCULOS PRATICADOS}

O planejamento pedagógico do PVCR se estabelece a partir de uma plataforma de objetivos complexos e paradoxais na medida em que se entrecruzam bandeiras político-pedagógicas incongruentes, tentando compatibilizar o que, a princípio, aparenta ser a principal contradição do planejamento curricular: preparar uma grade pautada nas concepções tradicionais de currículos conteudistas. Tais noções visam ao sucesso no exame vestibular e apresentam um objetivo de caráter imediatista, confrontando tal concepção com a preocupação de preparar politicamente os alunos por meio de um currículo baseado nas teorias críticas e pós-críticas, cujo objetivo é mais amplo, com caráter coletivista. Daí decorre o grande desafio vivido por cada professor ou professora, voluntários nesse movimento social de educação popular, de adequar o "programa ideal" ao programa possível, o que tornava o programa mais participativo, além de contribuir para a formação dos alunos que chegassem à universidade de modo a torná-los dispostos a entrar nos embates políticos que trazem 
como temário as desigualdades sociais e, sobretudo, prepará-los para uma vida de lutas políticas pela emancipação e pela promoção social das populações às quais pertencem. Cabe explicitar que o fundamento teórico em que sustento as classificações curriculares em tradicionais, críticas e pós-críticas, apoiam-se em Silva

(...) Neste sentido, as teorias críticas de currículos, ao deslocar a ênfase dos conceitos simplesmente pedagógicos de ensino e aprendizagem para os conceitos de ideologia e poder, por exemplo, nos permitiram ver a educação de uma nova perspectiva. Da mesma forma, ao enfatizarem o conceito de discurso em vez do conceito de ideologia, as teorias pós-críticas de currículos efetuaram um outro importante deslocamento na nossa maneira de conceber o currículo. (2004, p. 17)

$\mathrm{O}$ autor sugere ainda que, ao percorrermos as diferentes teorias de currículos, é possível pensar que tais teorias “(...) resume[m] as grandes categorias de teorias de acordo com os conceitos que elas, respectivamente, enfatizam". (SILVA, 2004)

Os conteúdos e as práticas curriculares do PVCR se vêem imbuídos da predominância de dois eixos programáticos: um quantitativo-cientificista e outro político-qualitativo. $\mathrm{O}$ eixo referente à construção de uma grade curricular com um quantitativo de conteúdos que são julgados necessários para os exames vestibulares não traz tantas dificuldades de elaboração. São feitas reuniões entre os coordenadores e estabelecidos conteúdos que precisam ser ensinados com base nas ementas oferecidas pelas universidades. São escolhidas como referência as instituições UFRJ, UERJ, UFF, UNIRIO e PUC. Os conteúdos que são comuns a todas as ementas são automaticamente incorporados à grade curricular do "pré". Entre aqueles que não são comuns, a maioria é descartada, dando-se prioridade, apenas, aos que aparecem na ementa da UFRJ. Assim tem sido construída a grade curricular do eixo dos conteúdos de treinamento para os exames vestibulares.

A construção do programa para o outro eixo, o da "formação" crítico-política, é mais complexa. Não é possível estabelecer um programa formal e rígido para esse eixo, pois ele se complementa e ganha concretude nas imprevisibilidades do cotidiano. O que se faz é tentar traçar um temário com atividades político-socializadoras para o ano letivo.

Assim, o segundo eixo, no qual reconheço maior potencial emancipatório, é estruturado a partir de dois dispositivos: um já tradicionalmente conhecido nos cursos vinculados ao Pré-Vestibular para 
Negros e Carentes (PVNC), que é a disciplina "Cultura e Cidadania"; o outro foi denominado "Orientações político-pedagógicas".

Para a disciplina "Cultura e Cidadania", é organizado um temário para debates. A concepção da disciplina a aproxima das teorias pós-críticas de currículos, principalmente no que diz respeito ao currículo multiculturalista e à narrativa étnica e racial, tal como foi apresentado por Tomaz Tadeu da Silva em Documentos de identidades (2004).

O segundo dispositivo, denominado "Orientações políticopedagógicas”, foi organizado com objetivos múltiplos, entre os quais trabalhar algumas orientações técnicas básicas de elaboração de resumos e fichamentos, complementado pelo aporte crítico-teórico oriundo de um conjunto de textos com certa densidade teórica, apresentando aos alunos alguns autores clássicos da literatura política, como $O$ capital, de Marx, Pedagogia do Oprimido, de Paulo Freire, etc. A dinâmica da aula se faz a partir de leituras individuais, complementadas pelo uso das técnicas de leitura exploratória, leitura com marcação das idéias principais do autor. Após a leitura e a esquematização do texto, inicia-se um processo de debate cujo interesse é ampliar a consciência política dos participantes e seus compromissos com o movimento. Porém as práticas cotidianas imbuídas dos sonhos e interesses individuais dos alunos demonstram que os resultados esperados pelo currículo planejado não se consubstancializam, tal como planejado. Na reflexão sobre a possível incoerência entre os objetivos das ações pedagógicas voltadas para os conteúdos formais e as ações com objetivo de formação crítico-política, percebe-se, finalmente, que o potencial emancipatório está na complementariedade entre as duas abordagens. Não há contradição entre a proposta de escolarização e a de politização. Elas são concomitantes e complementares no processo de emancipação.

Como já foi dito, um dos grandes desafios do PVCR é elaborar estratégias político-pedagógicas que possibilitem a preparação diferenciada, não só para o ingresso na universidade, mas, principalmente, para a efetivação de processos emancipatórios que possam estar consubstanciados no projeto de vida individual e profissional de cada aluno que passa por essa experiência de educação popular.

Uma das tentativas de iniciar um processo de regulamentação e homogeneização do trabalho dos voluntários do PVCR foi a construção das ementas das diferentes disciplinas. Essa estratégia de organização programática configura uma tentativa da coordenação do PVCR de criar um mecanismo regulador para as ações dos professores voluntários. Esse tipo de planejamento das atividades acabou aproximando o PVCR do 
modelo estratégico-regulador característico das instituições oficiais de ensino, apesar das práticas dialógicas que também desenvolvemos.

Cada professor recebia da coordenação a proposta de grade curricular feita a partir das ementas das universidades, como já mencionado, e tinha a possibilidade de opinar e modificá-la em função da sua experiência anterior e dos saberes tecidos a partir delas. A idéia era a de adaptar aquele programa ideal das possibilidades concretas dos alunos do curso, transformando-o no "programa possível". Era pedido para que cada professor, de acordo com sua especialização e sua experiência docente no movimento, fizesse as alterações necessárias nos programas e desse retorno à coordenação pedagógica, para que, assim, pudesse ser "oficializado" o programa das disciplinas para o ano letivo. Essa era também uma busca para tornar o planejamento mais participativo.

É bom lembrar que nenhuma regra é aplicável à realidade tal e qual, daí a necessidade de captar a dinâmica do cotidiano para compreender as aparentes contradições nos encaminhamentos da coordenação. Não existe constância de comportamentos de turma para turma ou de um ano para o outro. Cada turma tem sua dinâmica e suas especificidades. É preciso compreender os esquemas de operações utilizados pelos alunos e pelos professores para lidar com as normas vindas da coordenação, de acordo com os diferentes estilos de ação de cada um e de cada grupo dentro desse campo. As diferentes maneiras de (con)viver no espaço-tempo do PVCR apontam os limites do poder instituído e de suas estratégias de regulação. Quando se corporificam na dinâmica real da vida cotidiana, as normas são usadas e transformadas pelos praticantes (CERTEAU, 1994) de acordo com seus interesses e possibilidades (OLIVEIRA, 2003).

Certeau (1994) sugere que as estratégias são ações que, graças ao postulado de um lugar de poder, elaboram lugares teóricos (sistemas e discursos totalizantes) capazes de articular um conjunto de lugares físicos em que as forças se distribuem. Porém, os atores envolvidos no cotidiano do PVCR desenvolvem uma hábil e criativa utilização do tempo, das ocasiões e dos jogos, o que introduz na dinâmica do movimento limites às regras impostas. Tais limites podem variar de acordo com as especificidades de cada turma e de cada voluntário envolvidos no processo.

Fazendo uma combinação entre o que cada um recebe e o uso que faz do que recebe, tivemos um exemplo desse limite quando, em determinado momento do ano, alguns alunos conseguiram a adesão da 
turma e promoveram um boicote às aulas de um professor-coordenador, na tentativa de demonstrar não só a insatisfação com as estratégias adotadas pelo PVCR, mas, principalmente, para tentar trazer outra lógica de organização e funcionamento para o movimento. Esse fato indica que os alunos têm uma percepção das relações de forças que se estabelecem no âmbito do movimento e criam para si um espaço de jogo em que explicitam maneiras de utilizar a ordem imposta sem abandonar o lugar do qual dependem para alcançar seus objetivos pessoais.

Para compreender, portanto, a dinâmica da realidade cotidiana do PVCR, é preciso ir às práticas de alunos e professores e não apenas às suas regras. Para trazê-las, vou primeiramente tratar dos relatos. Os relatos das histórias de vida e das táticas utilizadas durante as trajetórias de alguns ex-alunos do PVCR (agora na condição de quem já passou pelo processo e está como professor e coordenador) e dos atuais alunos, que também narram suas astúcias para conseguirem estudar numa realidade tão adversa e, muitas vezes, hostil, ganham sentidos subversivos quando entendidos numa perspectiva certeauniana, como ações táticas ou astúcias do fraco.

Existe com certeza um conteúdo do relato, mas pertence, ele também, à arte de fazer um golpe: ele é desvio por passado ("no outro dia", "outrora") ou por uma citação (uma "sentença", um "dito", um provérbio), para aproveitar uma ocasião e modificar um equilíbrio por uma surpresa. O discurso aí se caracteriza não tanto por uma maneira de se exercer mas antes pela coisa que mostra. Ora, é preciso entender outra coisa do que a que se diz. O discurso produz então efeitos, não objetos. É narração, não descrição. É uma arte do dizer.O público ali não se engana. Do "truque" (o que basta saber para fazêlo) - mas também da revelação/vulgarização (o que indefinidamente é preciso saber) - ele diferencia a arte, como as pessoas ordinárias a que Kant se refere (aliás, onde está ele mesmo?) distinguem facilmente o prestidigitador do homem que dança na corda. Algo na narração escapa à ordem daquilo que é suficiente ou necessário saber e, por seus traços, está subordinado ao estilo das táticas. (CERTEAU, 1994, p. 154)

Nessa citação, o autor diferencia o ilusionista (prestidigitador) do artista (o homem que dança na corda bamba). Quem relata uma história, astuciosamente, modifica a forma de contar, sai do previsível e subverte a ordem e o esperado. Ou seja, o fato de o relato inventar coisas não significa que seja enganação. A idéia do relato fantasiado é exercer uma função política. Narrando fantasiosamente a realidade, os relatos mantêm abertas possibilidades transgressoras, contrapõem-se ao poder instituído, "inventando" uma realidade mais favorável ao fraco. Quando um ex- 
aluno inventa uma história de como enganava o patrão (o poder) para participar das atividades socializadoras do "pré" no horário de trabalho, ele está transformando esse relato numa possibilidade de subversão de um poder instituído (o patrão). Esse relato é uma arte do discurso que traz com ela uma arte de fazer-subverter.

Assim, o relato é parte integrante dos currículos praticados no PVCR. Dão outros significados às práticas político-pedagógicas. Isso nos remete à idéia de tessitura das redes de significados apresentada por Oliveira (2003), na qual valores são transmitidos e questionados. Parafraseando a autora, é possível perceber que, no espaço de aprendizagem do PVCR, se tece uma multiplicidade de redes de saberes, para além daquilo que a organização curricular e a forma de aplicação de conteúdos podem prever. Nesse cotidiano, conteúdos, valores e saberes que se enredam ganham outros significados. Passam a ser percebidos na sua complexidade na medida em que é possível analisar e refletir, juntos, as chances e oportunidades históricas que cada um já teve para a ascensão social, a partir da escolarização. É possível questionar valores transmitidos.

Isso significa dizer que, nas nossas atividades cotidianas, os currículos que criamos misturam elementos das propostas formais e organizadas com possibilidades que temos de implantá-las. Por sua vez, tais possibilidades se relacionam com aquilo que sabemos e em que acreditamos, ao mesmo tempo em que são definidas na dinâmica de cada turma, dos saberes dos alunos, das circunstâncias de cada dia de trabalho. Ou seja, cada conteúdo de ensino, repetidamente ensinado ano após ano, turma após turma, vai ser trabalhado diferentemente por professores diferentes, em turmas diferentes, em situações diferentes. (OLIVEIRA, 2003, p. 81)

É nesse sentido que compreendo a idéia de currículos praticados nesse tipo de movimento social de educação popular. E essa compreensão ajuda a pensar a complexidade de operacionalizar as propostas políticopedagógicas do PVCR.

Assim, os relatos vão criando realidades possíveis ao narrarem suas astúcias. Vão se constituindo em quadros-memórias de ações táticas que podem dar certa formalidade às práticas curriculares no/do PVCR.

O cotidiano do PVCR não é só um palco de consensos, como já vimos. Pelo contrário, sua grande potência está nos conflitos e nos modos como são geridos e narrados pelos diferentes atores. Talvez o principal deles seja o que opõe, em muitos momentos, os projetos individuais de aprovação no vestibular de alguns alunos ao projeto político de conscientização que integra a proposta pedagógica do PVCR. Muitas táticas para 
evitar o que alguns consideram "perda de tempo" das aulas de "Cultura e Cidadania" e "Orientações Pedagógicas" e o uso deste tempo para aulas das disciplinas escolares formais, que "caem" no vestibular, são postas em prática por alunos, ao mesmo tempo em que coordenação e professores buscam manter o respeito às regras. Independentemente de opiniões favoráveis a um ou a outro "lado" desse conflito, a gestação de táticas como contraposição às imposições advindas do poder instituído evidencia amadurecimento político e pode ser caracterizada como prática emancipada, que, contraditoriamente, é aquilo para o que a disciplina "Cultura e Cidadania" pretende preparar os alunos.

Essa tensão talvez seja um dos elementos fundamentais na potencialização dos dilemas pedagógicos do PVCR. À medida que o ano letivo transcorre, vão se agudizando os conflitos entre os atores que operam no cotidiano e que defendem a busca da realização dos projetos e objetivos individuais dos alunos contra os atores que operam no campo organizacional e político e que preferem investir no projeto político de ampliação do quadro de militantes e na complementação da intergeracionalidade no movimento. Essa complexidade nos remete a outro caminho de reflexão epistemológica que ajuda a pensar e/ou compreender os constantes dilemas que se apresentam nos "prés" populares e que provocam grande evasão nos cursos. Nesse sentido, o conceito de tática subversiva pode ampliar a compreensão de tais dilemas. As táticas, seguindo ainda a linha epistemológica de Certeau, não são ações calculadas previamente.

A tática é movimento "dentro do campo de ação do inimigo" como dizia von Büllow, e no espaço por ele controlado. Ela não tem portanto a possibilidade de dar a si mesma um projeto global nem de totalizar o adversário num espaço distinto, visível e objetivável. Ela opera golpe por golpe, lance por lance. Aproveita as ocasiões e delas depende, sem base para estocar benefícios, aumentar a propriedade e prever saídas. $O$ que ela ganha não se conserva. Este não-lugar lhe permite sem dúvidas mobilidade, mas numa docilidade aos azares do tempo, para captar no vôo as possibilidades oferecidas por um instante. Tem que utilizar, vigilante, as falhas que as conjunturas particulares vão abrindo na vigilância do poder proprietário. Aí vai caçar. Cria ali surpresas. Consegue estar onde ninguém espera. É astúcia (1994, p. 100-101).

Os saberes forjados no/do cotidiano dos alunos do PVCR são suportes que permitem o desenvolvimento de táticas subversivas, indispensáveis para a constituição de uma rebeldia, fundamental ao processo de emancipação. Por isso, um dos objetivos pedagógicos do PVCR é pro- 
mover uma via de mão-dupla na qual tanto o sujeito que aprende quanto o sujeito que ensina sejam aprendentes e ensinantes, numa relação dialógica em que ambos estejam dispostos a sofrer transformações nas suas concepções, possibilitando o enredamento de valores e o desenvolvimento de novas relações sociais que partam do princípio do diálogo, e não da imposição.

Ao fazermos um mergulho no universo desse movimento, é possível perceber os sinais de resistência e transgressão às regras impostas e o exercício de práticas emancipadas e emancipatórias. Percebemos que os alunos do pré-Rocinha, nas suas ações cotidianas, transformam sua realidade, fazendo usos táticos das regras impostas, elaborando novos conhecimentos. Com o uso que fazem das regras que lhes são impostas e com seus saberes/fazeres forjados no cotidiano, constroem suas casas, seus espaços sociais, suas vidas. Modificam a escola, que, vinculada aos saberes dominantes, representantes de um saber supostamente superior, dificilmente abre espaço para as culturas "inferiores". Trazem para ela seus conhecimentos e os valores de "camadas populares" de moradores de favelas, aqueles que não são sequer reconhecidos como saber. É comum ouvirmos de profissionais da educação que funk é coisa de bandido e que o Hip-Hop faz apologia disso ou daquilo, embora sejam apenas manifestações culturais legítimas de determinados grupos sociais. Há muitos outros exemplos de discriminação de práticas e valores sociais e culturais dessas populações pela escola convencional e de táticas usadas para combatê-las.

No PVCR, as ações dos alunos apresentam-se indissociáveis das práticas cotidianas experienciadas por eles na comunidade. Exemplo interessante é o episódio que envolveu um conflito entre traficantes de facções rivais, cujos reflexos ofereciam constantes ameaças à integridade física de todos os indivíduos. A convivência com essa cruel realidade obrigou os alunos a construírem táticas cuja compreensão requer não só o contato com eles por algumas horas semanais, mas uma (con)vivência maior. Os alunos, devido à permanente exposição à violência, não perceberam o estado de pânico de um professor voluntário (morador de um bairro da zona sul do Rio, que oferecia um distanciamento desse grau de violência urbana, garantindo, inclusive, um "estado" de tranqüilidade maior do que o dos moradores-alunos da Rocinha), que, aterrorizado com o barulho dos tiros, perguntou se conseguiria ir embora para casa. A resposta veio num tom de brincadeira e de naturalidade: "Não se preocupa não, professor. Foi só uma granada que explodiu, mas foi um 
pouco distante daqui!". Tal resposta pode ter tido alguma influência sobre o fato de que, depois desse dia, o professor nunca mais voltou a dar aula no PVCR.

Esse relato demonstra claramente como a dinâmica local está imbricada no cotidiano do curso e o quanto ela o influencia. A compreensão desse cotidiano requer sensibilidade que extrapola a "boa vontade" de ser voluntário. Especificamente nesse episódio narrado, o PVCR ficou sem um professor de Física. O diálogo necessário entre o movimento e o vestibular forçou os vários atores (alunos, coordenadores e professores) a utilizarem diversas táticas não pensadas nas estratégias iniciais (tentativas de remanejamento de professores, mobilização de várias pessoas na colação de cartazes nas universidades, etc.).

Os pré-vestibulares de corte comunitário trazem essas idiossincrasias. O PVCR já precisou várias vezes adequar a sua rotina (horários de términos de aulas, aulas extras, calendários, etc.) em função do contexto local. Com isso, deduz-se que o cotidiano do pré-Rocinha é complexo, porém faz-se palco propício às práticas contra-hegemônicas e às táticas subversivas.

\section{TRABALHO, CULTURA, FORMAC̣ÃO E PESQUISA}

Nesse sentido, o PVCR passa a representar, então, não só um espaço de escolarização e reflexão crítica, mas o lugar propício para o desenvolvimento de uma vontade que se converte em ações táticas, operacionalizadas por meio de articulações com grupos que atuam na favela a partir de outras perspectivas emancipatórias. Os grupos de estudos que se formam em horários inventados pelos alunos, aproveitando os horários vacantes por problemas pessoais dos professores e/ou eventuais imprevistos do próprio local (tiroteios, assassinatos...), passam a fazer parte de um conjunto de ações alternativas políticas que envolvem outras lógicas de aprendizagem. A promoção de eventos políticos com o objetivo de problematizar questões envolvendo outros atores políticos na luta pela democratização do acesso ao ensino superior e a promoção de eventos beneficentes, com o objetivo de arrecadar fundos para o pagamento das taxas de inscrição nos vestibulares daqueles alunos que não têm condições de arcar com essa despesa, são algumas, entre muitas, ações emancipatórias que pululam nos currículos praticados nos pré-vestibulares comunitários e que podem ser invisibilizadas pelas formas de pesquisa universalizantes que estudam os movimentos de educação popular.

As generalizações tendem a não captar as ações táticas das práticas não-autorizadas que subvertem as regras dominantes e transformam 
os lugares e as funções sociais impostas, fazendo uso do que está disponível. É isso que inspira a ida ao cotidiano do PVCR para tentar compreender as complexidades dos currículos praticados e, com isso, propor intervenções para os dilemas pedagógicos mais freqüentes nos pré-vestibulares de corte popular, tais como: a grande evasão que ocorre durante o ano letivo e a ampliação dos laços afetivos e sociais dos atores com a proposta política do movimento, principalmente a que diz respeito à necessidade de constantes renegociações e reestruturação do quadro de voluntários, com o retorno dos alunos que entram nas universidades.

Há, também, as atividades político-socializadoras realizadas durante o ano letivo no PVCR. Essa parte é bastante complexa e desafiadora. Nela, as propostas estão estritamente imbricadas às condições sociais de cada aluno. É preciso fazer a leitura dos gestos e olhares que pululam nas discussões do grupo para não transferir para aquele espaço o que muitas vezes acontece nos espaços oficiais de ensino: a exclusão daqueles com menos condições de participação social. No PVCR, as atividades socializadoras (idas ao teatro, ao cinema, etc.) precisam ser definidas de modo a contemplar, tanto quanto possível, toda a diversidade presente. E muito esforço coletivo se faz para isso. Esses momentos propiciam aos alunos a possibilidade de realizar uma análise de conjuntura, na qual eles se percebem como sujeitos de um espaço complexo em que suas ações não são dissociadas do todo. Permitem, com isso, uma ação-reflexão sobre as bases que estabelecem os laços que os unem.

Esses momentos passam a ser incorporados às rotinas cotidianas e vão ampliando o manancial de possibilidades de compreensão do mundo dos alunos, na medida em que trazem novos fios e possibilidades de tessitura às redes de subjetividades que cada um é (SANTOS, 1995) e daí às relações intersubjetivas. Nesses processos de enredamento, os diferentes atores e as redes de relações intersubjetivas que se instauram criam novas conjunturas. Com isso, esses sujeitos vão re-significando as disposições incorporadas pelas estruturas, fazendo do cotidiano um espaço de criação de novas rotas para as suas vidas.

Segundo Pais:

A vida quotidiana pede sempre um elemento circunstancial. Vida quotidiana de quem? Em que situação? Em que contexto? Foi assim pela via do quotidiano, que senti necessidade de reflectir sobre o que se deve ou não entender por um contexto social. Pela via do quotidiano, ou seja, entendo o quotidiano como paradigma de toda uma série de interrogações: sobre o poder, as instituições, as representações sociais. É neste sentido, aliás, de significante flutuante do real-social, que a perspectiva do quotidiano se mostrará mais reveladora. $(2003$, p. 115) 
Assim, é possível pensar se o cotidiano do PVCR não estaria possibilitando a um grupo de moradores da Rocinha ampliar seus capitais social e cultural (BOURDIEU, 1986), promovendo um diferencial de práticas, em relação às práticas da maioria dos moradores da favela. Porém, mesmo com tal ampliação, os alunos do PVCR não podem ser pensados como uma elite, no sentido usual da palavra. Isso porque, mesmo se destacando de seus pares, seus capitais não parecem ser suficientemente relevantes para uma integração em outros espaços sociais fora da favela ${ }^{3}$ e nem garantir espaço no mercado de trabalho. Os capitais adquiridos pelos alunos durante o "pré" e, também, quando passam para as universidades são tensionados às representações difundidas pela mídia, que os estigmatiza e que são, muitas vezes, internalizadas pelos nãomoradores de favelas. É como se o simples fato de serem moradores da favela já os subtraísse em relação à mobilidade e à possibilidade de ascensão socioeconômica fora dela. É possível pensar que, por mais que um morador da Rocinha usufrua de determinados capitais na favela, ainda assim, a promoção social e o status que os alunos adquirem dentro dela com estes capitais não são convertidos em capitais sociais plenamente aceitos por toda a sociedade.

Por outro lado, ao participar das reuniões e dos embates que visam a compreender essas questões e buscar soluções para muitos dos dilemas do cotidiano no "pré", os professores e coordenadores de camadas sociais diferentes daquelas que vivem na Rocinha, que mantêm laços afetivos e culturais diversos com a comunidade, ampliam em suas agendas suas rotinas e preocupações com a educação e a formação de outras pessoas. Nesse sentido, os movimentos sociais de educação popular tais como os pré-vestibulares populares, que compartilham alguns saberes intergeracionalmente e interclasses, são, hoje, sem dúvida, além de espaços de formação política, espaços de formação de professores.

Uma das funções latentes que se consubstanciam no espaço complexo de ação educativa dos "prés" populares é a possibilidade de articulação das inquietudes individuais, oriundas das incertezas de aplicabilidade do cabedal teórico adquirido na academia com a prática de ensino e a potencialidade de operacionalização do saber cotidiano da sala de aula, sem que esta tentativa de conversão esteja submetida a uma estrutura burocrática rígida. Isso possibilita a construção de um outro saber, mais prático, transformando, assim, uma iniciativa "solidária", ou militante, daqueles que se envolvem com um movimento social, em um estágio de vivência, cujo ganho, entre outros, é a experiência prática do exercício da 
docência num espaço não-convencional, que permite a auto-investigação da prática, configurando, assim, mesmo que inconscientemente, uma prática de pesquisa denominada "self-study".

Pesquisa auto-investigação pode ser definida como estudo feito pelo próprio indivíduo a partir da reflexão sistemática sobre sua própria experiência e tem como base o conhecimento prático. Tem como característica básica desenvolver uma conexão do "self" com o seu tempo, portanto a pesquisa "self-study" de qualidade requer que o pesquisador demonstre um equilíbrio particularmente sensível entre biografia e história. Esse equilíbrio é demonstrado pelo modo pelo qual a experiência individual pode prover "insights" e soluções para questões e inquietações consideradas de natureza pública, por outro lado, a teoria pública é utilizada para prover "insights" e alternativas para solução de questões privadas de cunho pessoal. A consideração desse equilíbrio na pesquisa constitui-se o cerne da autoinvestigação e é visto como o seu principal desafio. Em síntese é preciso articular a inquietação pessoal ou questionamento privado com as questões públicas de um tempo e lugar. (MARCONDES, 2004, p. 263)

No caso do PVCR, esse equilíbrio é tensionado a outros dilemas. Um dos mais evidentes é a tentativa de compatibilização de objetivos distintos que se materializam nos conflitos entre os projetos individuais dos alunos reforçados, no cotidiano, pela busca de um acúmulo de conteúdos disciplinares para que, assim, diminua a distância entre o sonho de passar no vestibular e a realidade cruel em que vivem, que constantemente insiste em dizer não. Por outro lado, há um grupo de coordenadores que atua no campo político e que, de certa forma, lida com o acúmulo de outros saberes e capitais sociais e políticos que os lança em outra escala de luta, mais voltada para o potencial político dessa formação, no mesmo cotidiano do movimento. Isso faz com que a maioria desses atores pense o movimento a partir da perspectiva de um projeto coletivo, cujos interesses em jogo estão além do bom resultado individual no vestibular.

Talvez seja na fronteira dessa tensão (coordenação/alunos) que se encontrem os professores "voluntários" no PVCR, que são muitas vezes pressionados a assumir uma posição quando as evidências dos conflitos são transformadas em pontos de pauta das assembléias gerais do movimento. Geralmente, o posicionamento dos professores é definido sob a pressão das circunstâncias, pelas afinidades de projetos societários e por seus próprios objetivos individuais. Por um lado, alguns alunos, cujo principal objetivo é alcançar a aprovação no vestibular, se organizam e se constituem como lideranças da turma, buscando, com isso, levar as decisões da assembléia à valorização do tempo de aulas com conteúdos 
das disciplinas escolares, otimizando o uso dos recursos (espaço-tempo do "pré" e mão-de-obra barata (gratuita) oferecida pelos professoresvoluntários). Por outro lado, os coordenadores e a cobrança por envolvimento maior com as propostas políticas e o compromisso com as esferas para além da sala de aula (tais como assembléias, encontros com outros "prés populares", participação nos eventos promovidos na favela com outros atores sociais da Rocinha, etc.). No meio, os professores voluntários do movimento, que se encontram nos interstícios desses conflitos que se instalam no cotidiano do PVCR.

Nesse contexto, os professores em formação nos/dos/com os "prés populares" se vêem obrigados a desenvolver estratégias didáticopedagógicas não pensadas e nem previstas nos cursos oficiais de licenciatura e de formação de professores. Tais estratégias são constituídas, criadas e construídas por meio dos enredamentos dos saberes práticos tecidos nas redes de intersubjetividades conflitantes e consensuais desses movimentos sociais. A maioria dos professores voluntários dos "prés populares” estão cursando a graduação ou são recém-formados. Isso faz com que eles, que na maioria das vezes estão tendo sua primeira experiência na sala de aula, sejam apresentados a uma dinâmica de prática de ensino em que o principal elemento de avaliação do seu desempenho e de feedback é a própria reflexão sobre sua prática e a auto-investigação baseada no equilíbrio entre as possibilidades teóricas trazidas da universidade e os insights provindos das experiências individuais no "Pré-vestibular popular". Com isso, é possível que esses novos professores, que estão desenvolvendo suas práticas de ensino nos movimentos sociais de educação popular, passem a desenvolver também uma prática de pesquisa "selfstudy" na medida em que auto-investigam as relações existentes entre os conteúdos das disciplinas que estão sendo formados para ensinar e a relevância que esses conteúdos têm em relação ao que será cobrado nos exames vestibulares. Esse exercício possibilita outro tipo de contato com os conhecimentos inerentes às suas disciplinas e muitos questionamentos políticos sobre os porquês da hierarquização de alguns conteúdos.

\section{PARA NÃO CONCLUIR...}

Lecionar uma disciplina em movimentos sociais como os "prés populares" significa expandir o conjunto de condições de possibilidades do devir professor. Significa, também, estar sendo inserido em outro circuito de saberes necessários às práticas docentes. Saberes que são compartilhados e enredados, principalmente, naqueles momentos do "não sei o 
que fazer agora", como, por exemplo, os rompantes de tiroteios na favela, que quebram a rotina das aulas no PVCR. Nesses momentos, os professores voluntários precisam aprender, compartilhadamente com os alunos, coisas que não sabem para lidar com tais situações. Nesses momentos, também, se mistura racional, emocional, afetivo, didático... O professor precisa se colocar por inteiro na situação. São tecidas novas redes de saberes que transformam não só o espaço do "pré", mas, principalmente, os indivíduos que nele se constituem.

Os professores do PVCR tensionam os textos e as noções trabalhadas na academia aos dilemas do cotidiano em que se encontram. A partir daí, criam-se outros saberes, os saberes da experiência, os saberes práticos oriundos de um cotidiano complexo, cujos valores pessoais e tradições de cada um são confrontados a outros valores e tradições que se pactuam naquele espaço.

Nesse sentido, o processo de auto-investigação mantém-se latente durante toda a prática de ensino dos novos futuros professores que atuam nos pré-vestibulares populares. Penso que tal processo aparece com mais nitidez nas reuniões e nos debates pedagógicos que expõem as fraturas entre os objetivos propostos (políticos e/ou pedagógicos), no início do ano, e os resultados que vão sendo alcançados. Essas reuniões são palco de conflitos que permitem enredamentos dos saberes práticos de cada professor, aluno e coordenador aos saberes acadêmicos. Essa dinâmica cotidiana se consubstancia em uma forma de ensino e aprendizagem não-convencional, porém eficaz no processo de emancipação.

\section{REFERÊNCIAS}

BOURDIEU, P. Razões práticas: sobre a teoria da ação. Campinas, SP: Papirus,1986.

BOURDIEU, P. Escritos de educação. Maria Alice Nogueira e Afrânio Catani (Orgs.). Petrópolis, RJ: Vozes, 1998.

CERTEAU, M. A invenção do cotidiano: artes de fazer. 2 ed. Petrópolis, RJ: Vozes, 1994. DELEUZE, G. Proust e os signos. Rio de Janeiro: Forense Universitária, 1987.

MARCONDES, M. I. A prática de ensino e a pesquisa sobre o saber prático dos professores. In: ROMANOWSKI, J. P.; MARTINS, P. L. O.; JUNQUEIRA, S. R. A. (Orgs). Conhecimento local e conhecimento universal: pesquisa, didática e ação docente. Curitiba, PR: Champagnat, 2004. p. 259-270.

OLIVEIRA, I. B. Certeau e as artes de fazer: as noções de uso, tática e trajetória na pesquisa em educação. OLIVEIRA, I. B. e ALVES, N. (Orgs.) Pesquisa no/do cotidiano das escolas. Sobre redes de saberes. Rio de Janeiro: DP\&A, 2001a.

OLIVEIRA, I. B. Currículos praticados: entre a regulação e a emancipação. Rio de Janeiro: DP\&A, 2003. 
OLIVEIRA, I. B. Aprendendo a ler/ver/ouvir as práticas das professoras no cotidiano escolar. Rio de Janeiro: UERJ/DP\&A. CD-Rom do III Seminário internacional As redes de conbecimentos e a tecnologia: textos imagens e sons, 2005.

OLIVEIRA, I. B. Boaventura e a educação. Belo Horizonte: Autêntica, 2006.

PAIS, J. M. Vida cotidiana: enigmas e revelações. São Paulo: Cortez, 2003.

SANTOS, B. S. Um discurso sobre as ciências. Porto: Afrontamento, 1989.

SANTOS, B. S. Pela mão de Alice: O social e o político na pós-modernidade. São Paulo: Cortez, 1995.

SANTOS, B. S. A crítica da razão indolente. Contra o desperdício da experiência. São Paulo: Cortez, 2000.

SANTOS, B. S. Por uma sociologia das ausências e uma sociologia das emergências. In: SANTOS, B. S. (Org). Conhecimento prudente para uma vida decente. São Paulo: Cortez, 2004. SANTOS, B. S. A Gramática do tempo. São Paulo: Cortez, 2006.

SANTOS, R. E. As quotas no vestibular da UERJ. Tempo e presença, Rio de Janeiro, n. 330, p.16 - 19 jul./ago., 2003a.

SANTOS, R. E. Racialidade e novas formas de ação social: o pré-vestibular para negros e carentes. In: SANTOS, R. E. e LOBATO, F. (Orgs). Ações Afirmativas: políticas contra as desigualdades raciais. Rio de Janeiro: DP\&A, 2003b.

SILVA, J. S. Por que uns e não outros: caminhada de jovens pobres para a universidade. Rio de Janeiro: Sette letras, 2003.

SILVA, T. T. Documentos de identidade: uma introdução às teorias do currículo. 2 ed. Belo Horizonte: Autêntica, 2004.

\section{NOTAS}

${ }^{1}$ Usarei a sigla PVNC para me referir ao Pré-Vestibular para Negros e Carentes. É importante ter cuidado para não confundir com a sigla PVCR, que usarei para denominar o Pré-Vestibular Comunitário da Rocinha.

${ }^{2}$ A Lei 10.639 altera a Lei 9.394, de 20 de dezembro de 1996, que estabelece as diretrizes e bases da educação nacional, para incluir no currículo oficial da Rede de Ensino a obrigatoriedade da temática "História e Cultura Afro-Brasileira". Ver: http://www.planalto.gov.br/ccivil/LEIS/2003/L10.639.htm

${ }^{3}$ Isso já foi sugerido em pesquisa realizada por Silva (2003), publicada no livro Por que uns e não outros.

${ }^{4}$ Alguns dos principais problemas são: falta de dinheiro para pagar as taxas de inscrição nos vestibulares, evasão de alunos, falta de adesão dos professores voluntários às iniciativas políticas de participação e de envolvimento com mobilizações em lutas locais e nas reivindicações pelo acesso ao ensino superior. 
Recebido: 30/08/07

Aprovado: 02/04/08

Contato:

Rua Caminho do Boiadeiro, $n^{\circ} 25$

Rocinha

Rui de Janeiro - RJ

Brasil

CEP 22451-350 